\section{INTERACTION AS A MEDIUM IN ARCHITECTURAL DESIGN}

Joanne Jakovich and Kirsty Beilharz, Key Centre of Design Computing and Cognition, University of Sydney, NSW 2006 Australia.

E-mail: <joanne@jakovich.net>.

The recent integration of sensor-based interactive systems into buildings presents a significant aesthetic opportunity for architectural design. Beyond static, permanent structures, architecture can utilize sensor technologies to develop dynamic responses to human needs, expanding the creative palette of the architect to incorporate computer-mediated information exchange between inhabitants and the environment: interaction. This opportunity, however, remains largely unexplored since the conventions used to conceive, represent, and hence design architecture currently lack the capacity to incorporate the real-time and dynamic nature of interaction, precluding its use as a fundamental medium within which to design and build.

While the notion of "medium" is less familiar in architecture than in art, the specification of form and materials (e.g. steel, glass, lighting) implements creative expression in the mediums of space, light and time. These articulations influence human experience and behavior, implying that traditional architectural design anticipates, and arguably orchestrates, human interaction in and with the constructed space. Technological developments introduce a new dimension to this relationship; behavior within the space not only is an outcome of design but also is used to drive dynamic architectural elements in real-time: mechanical walls/doors/floors, operative surfaces, media projections, dynamic furniture, digital soundscapes, haptic climates, ambient info-displays, etc. Thus the behavior-response cycle informs and shapes design decisions and brings to light the necessity to reconceive static models of space.

Through our creative practice spanning interactive art and architecture, we are exploring the aesthetic potential of interaction, challenging and marrying concepts from interactive art and architecture to develop an understanding of interaction as a creative medium in which to design space. As a platform for further experimentation, we present a four-part framework to redefine the relationship between architecture and interaction in this new hybrid domain of spatial practice.

\section{Merging Trajectories}

As an intangible, temporal form of communication, interaction seems improbable as a medium for creative expression when compared to other visual or haptic media. The pioneering work by artist-programmer Myron Krueger in the early 1970 s was first to establish its aesthetic potential. Krueger developed a series of "responsive environments" in which the audience could use full body gesture to interact with an array of spatially projected digital media. He discovered that the composition of the relationships between action and response drove the aesthetic experience, while the beauty of the visual and aural display was secondary. Notably, Krueger proposed "response" as a "new art medium based on real-time interaction between men and machines" [1]. More recently, interactive soundspace artist David Rokeby describes the "construction of experience" as the creative goal of the interactive artist and argues that the content of the artwork lies in the interactive experience itself [2].

In this way, the traditional dichotomy of audience and artwork dissolves. Cornock and Edmonds reframed the audience as "participant," proposing a systems-oriented framework for interactive art [3]. In this view, human participation drives generation of the artwork and is conceived as an integrated component of the art system. Building on this, Paine uses the analogy of dialogue to describe the reciprocality and contextdependency that characterizes interaction in the system [4]. By conceptualizing the art environment as a multi-part system varying over time, the artist is able to focus on the higher level structures that influence dynamic outcome rather than tangible elements such as form, color and so on.

\section{Framework}

The following presents a four-part framework for conceiving and implementing interaction as a medium in architecture. It is proposed as an analytical ground point to base practice, research and pedagogy occurring at the intersection of interactive art and architecture, and invites the reader to re-frame the ways in which we conceive and describe these.

\section{Architecture}

- Architecture is the theoretical and practical art of creating a plan of a complex

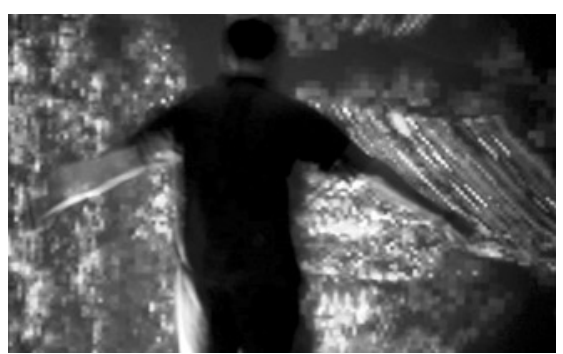

Fig. 1. Sonic Tai Chi (2005). ( Joanne Jakovich \& Kirsty Beilharz) Interactive gesture-activated space. (Photo $\odot$ Greg Turner)

object, or system, intended for human inhabitation or use.

- A system is a complex of interacting and interrelated components. A system has structure and, through interaction, behavior.

- Structure is the interrelationships within a system. It defines the behaviors between components and the behavior of the system overall. Structure may be fixed, responsive, adaptive, or autonomous.

- The human component, which is the human inhabitant or user, is an equal and integrated part of the system. For this reason, architecture is always concerned with human interaction with constructed systems.

- The structure consists of the subjective mapping from elements of the human experience to elements of other components of the system. This is the central creative concern of the architect.

- An architectural plan is primarily specified through structure. However, the medium in which this is implemented affects both the specification and the applied outcome.

- Once implemented, an architectural artifact is a system upon or within which human patterns of behavior adopt and adapt the relationships initially specified in the structure.

\section{Medium}

- A medium is an intermediate condition between two states. In creative practice, this implies that a medium is the condition between states of intention and realization.

- A condition is itself a state-it is a state of transition, or transformation. A medium is a means for transferring or transforming information, e.g. an idea, into another form of that information, e.g. a creative representation.

- A medium is a means for exchange. It is the method for creative expression, but also for creative interpretation. In this 
iterative way, it is a machine for continual creative exploration.

- A medium is a method, but it is not a material. A material is the specific substance or hardware chosen to implement the method, e.g. both a woodblock and an inkjet printer are materials used in the medium of print.

- The characteristics of a medium however, can be expressed according to the shared affordances and constraints of its materials. And in this way, a medium is both limited and enabled by the technologies available.

\section{Interaction}

- Interaction is the combined reciprocal action between two or more agents that have an effect on each other.

- Agents are (some of) the components, or elements of components, in a system. - An agent may be any human, computer, building or software system, for example, that has the capacity for producing a non-predetermined response or an action - that is, a response that is based on the specific information and context acquired from the current interaction.

- Agents possess a means for receiving information from others, and for expressing (displaying) information in return.

- Interaction produces feedback. Feedback is the direct and implicit information about how actions are interpreted by the opponent agent(s).

- Feedback occurs directly through reciprocated action, or indirectly through the overall effect of system actions.

Feedback motivates and informs further actions.

- Through reciprocal action, a dialogue develops which is specific to the present interaction. The dialogue is not repetitive, but grows based on information exchange over time.

- The dialogue is a unique temporal account of the interaction. Crossreferencing of these accounts produces generalized rules about the cause and effects of actions.

\section{Interaction as a Medium in Architecture}

- Interaction is the real-time condition between two or more agents that acts as a mechanism for exchange. That is, interaction drives exchange because feedback informs action.

- As a mechanism of exchange, interaction has the potential to communicate creative ideas. Ideas are expressed inherently in the structure of the system that enables interaction.

Fig. 2. Joanne Jakovich, Jin

Hidaka \& Satoru

Yamashiro, Soft

Inversions (2006).

Large-scale in-

stallation using

projections on the

structural mem-

bers of an aban-

doned turbine

hall. (@) Joanne

Jakovich, Jin

Hidaka \& Satoru

Yamashiro. Photo

(C) Kota Arai.)

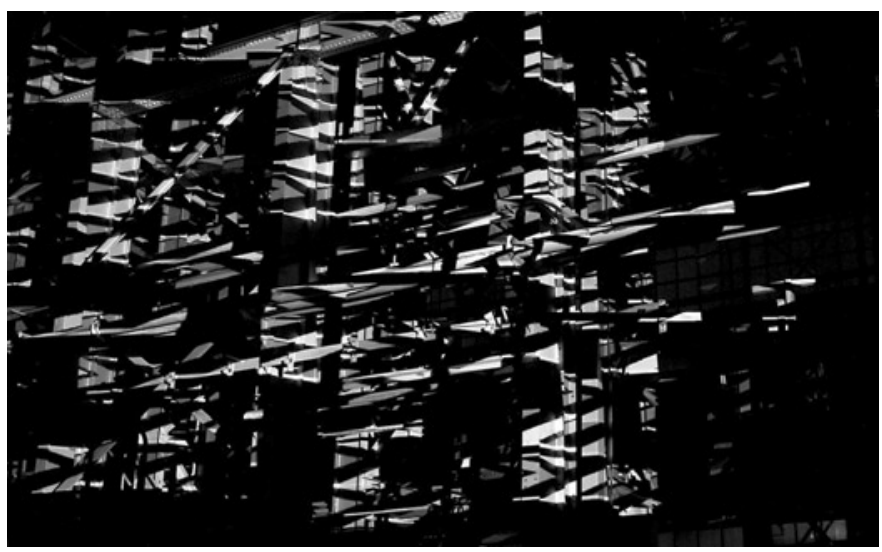

- The design of the system structure aims to achieve functional and aesthetic spatial goals through the medium of interaction. This is the main creative focus of the architect.

- As a medium in architecture, with its own inherent affordances and constraints, interaction can be used to bring certain qualities to a built environment, just as do light, texture, form and so on. - The aesthetics of a space are hence conceived according to how one interacts both directly and indirectly with the environment, through exploratory gesture and/or interaction in addition to passive perception of conventional spatial media.

Implications for Implementation Our creative explorations of this framework have unearthed a rich discussion on the role of technology in interaction. While we have experimented with the use of generative cellular automata systems in gesture-activated soundspaces (Fig.1) [5] we have also explored the extent to which simple interaction is augmented by the overlaying of the digital display with physical host space itself (Fig. 2) [6]. We discovered that implementing interaction as a medium does not require expensive or complex hardware and software systems, but rather requires a great deal of experimentation in the developmental phase to ascertain the particular aesthetic qualities of the mode of interaction in use. Indeed, the capacity to design and construct simultaneously, and to iteratively re-design/reconstruct based on user testing, is an exciting feature of this medium. Unlike previous modes of design which involved envisioning a future built space using sketches and models, this process enables a live mode of observation and modification that occurs in parallel to full-scale construction.

\section{The Future}

It is interesting that some of the key exponents of interactive art are architects and that the work of eclectic groups like Archilab [7] embodies this very synergy of fantastical, dynamic structures that favor artistic outcomes more than serving architectural functions. This same adventurousness pushes boundaries of imagination, unfettered by constraints of domain specific techniques. Thus the framework presented formalizes the relationships between conventionally, perhaps artificially, distinct disciplines of architecture and interactive art and elicits ways in which one can inform the other. We envision that through the medium of interaction, new creative expression and understanding of space can augment the richness and inherent dynamism of the architectural and urban systems we inhabit.

\section{References}

1. Myron Krueger, "Responsive Environments," in Randal Packer and Ken Jordan, eds., Multimedia: From Wagner to Virtual Reality (New York, U.S Norton \& Company Ltd., 2001).

2. David Rokeby, "The Construction of Experience," in Clark Dodsworth, ed., Digital Illusion: Entertaining the Future with High Technology (New York, U.S.: ACM Press, 1998).

3. Stroud Cornock and Ernest Edmonds, "The Creative Process where the Artist Is Amplified or Superseded by the Computer," Leonardo 6, No. 1 (Winter 1973) pp. 11-16.

4. Garth Paine, "Interactivity: Where to from Here?," Organised Sound 7, No. 3 (2002) pp. 222224.

5. Joanne Jakovich and Kirsty Beilharz, "'Sonic Ta Chi': Auditory Gestures in Reactive Soundspaces,' in The Second Australasian Conference on Interactive Entertainment (Sydney, Aus.: Creativity \& Cognition Studios Press, 2005) p. 243.

6. Soft Inversions (2006),

<http://www.jakovich.net/19.php>, accessed 3 March 2007.

7. Marie-Ange Brayer, Frederic Migayrou and Fumio Nanjo, Archilab's Urban Experiments: Radical Architecture, Art and the City (London, U.K.: Thames \& Hudson, 2005). 


\section{LEONARDO}

\section{Leonardo}

Volume 40, Number 4, August 2007

View Cover Art

\section{Contents}

\section{Editorial}

Edmonds, Ernest A., 1942-

- Research on and from within Creative Practice

[Access article in PDF]

Subject Headings:

- Art and technology.

\section{Special Section: The Fire Arts of Burning Man}

Kristen, Christine.

Brill, Louis M.

- The Fire Arts of Burning Man

[Access article in PDF]

Brill, Louis M.

- Special Section Introduction: A Passion to Burn

[Access article in PDF]

Subject Headings:

- Burning Man (Festival)

- Installations (Art) -- Nevada -- Black Rock Desert.

- Color Plates

[Access article in PDF]

Kristen, Christine.

- Playing with Fire

[Access article in PDF]

Subject Headings:

- Burning Man (Festival)

- Installations (Art) -- Nevada -- Black Rock Desert.

Hosking, Lucy.

- Satan's Calliope

[Access article in PDF]

Subject Headings:

- Hosking, Lucy. Satan's calliope [visual works] 